\title{
Effect of compressed plasma flow on Tantalum-Titanium thin layer deposited on silicon substrate
}

\author{
Amir Hossein Sari ${ }^{1}$, Valentin Mironovich Astashynski ${ }^{2}$, Anton Mikhailovich Kuzmitski ${ }^{2}$, \\ Vladimir Vasilevich Uglov ${ }^{3}$
}

${ }^{1}$ B. I. Stepanov Institute of Physics, National Academy of Sciences of Belarus, 70Nezavisimosti Ave., Minsk 220072, Belarus

${ }^{2}$ A.V. Luikov Heat and Mass Transfer Institute, National Academy of Sciences of Belarus, 15, P. Brovki Str., Minsk 220072, Belarus

${ }^{3}$ Belarusian State University, Nezavisimosti Ave., Minsk 220030, Belarus

\section{Email address:}

a.sari@dragon.bas-net.by(A.H. Sari)

\section{To cite this article:}

Amir Hossein Sari, Valentin Mironovich Astashynski, Anton Mikhailovich Kuzmitski, Vladimir Vasilevich Uglov. Effect of Compressed Plasma Flow on Tantalum-Titanium Thin Layer Deposited on Silicon Substrate. International Journal of Materials Science and Applications. Vol. 3, No. 3, 2014, pp. 92-99. doi: 10.11648/j.ijmsa.20140303.14

\begin{abstract}
The interaction of a dense compressed nitrogen plasma flow with a system of Ta-Ti layers on a silicon substrate has been investigated. This plasma flow was generated in a quasi-stationary pulsed plasma accelerator that can provide a supersonic high energy plasma flux. The plasma pulse duration, discharge current, concentration, and energy densities absorbed by the target were $100 \mu \mathrm{s}, 80 \mathrm{kA}, 10^{18} \mathrm{~cm}^{-3}$, and $3-13 \mathrm{~J} / \mathrm{cm}^{2}$ respectively. The samples were exposed to a single plasma pulseor to a series of pulses and were characterized by scanning electron microscopy, X-ray diffraction, and energy dispersive X-ray analyses. The result showed that the changes in the elemental and structure phase compositions depends on energy and number of plasma pulses. Formation of $\mathrm{Ti}_{5} \mathrm{Si}_{3}$ and $\mathrm{Ta}_{2} \mathrm{~N}$, are the main results of the current research.
\end{abstract}

Keywords: Pulsed Plasma, Surface Modification, Metal Silicide

\section{Introduction}

Quasi-stationary high-energy plasma flux with a power density above $10^{9} \mathrm{~W} / \mathrm{m}^{2}$ and duration of $\sim 100 \mu \mathrm{s}$ is an interesting source for material surface modification and empirical investigation of phenomena in the field of plasma-surface interaction. A magneto-plasma compressor (MPC) is a quasi-stationary plasma accelerator capable of producing a supersonic compressed plasma flow (CPF) with minimized electrode erosion [1,2]. In comparison with other available sources of high-energy plasma pulses, MPC generates plasma flows whose steady state duration is much longer than the flight time of plasma in the acceleration channel. Traditional plasma accelerators have achieved a certain limit in their development and application. Namely, in order to increase the plasma parameters, a discharge current of accelerator has to be increased. However, increase in discharge current causes intense potential jump near the anode and its heavy erosion. In contrast to this, the quasi-stationary plasma accelerators are a new generation. The plasma acceleration in a discharge device of these accelerators is accompanied by compressed flow formation at the outlet with plasma parameters much higher than those in inter-electrode gap. These accelerator systems are of special interest for development of new plasma technologies. High plasma parameters of compressed flows, together with a large discharge time duration enable efficient usage of such flows for material surface modification and obtaining new materials.

The created CPF has a high flow velocity, density, and temperature (up to $50 \mathrm{~km} / \mathrm{s}, 10^{18} \mathrm{~cm}-3$, and $\sim 2 \times 10^{4} \mathrm{~K}$ respectively), long discharge time duration $(\sim 100 \mu \mathrm{s})$, and high stability of a compression in a generated plasma flow. It has been also found that the plasma flow generated by quasi-stationary plasma accelerators can be used for simulation of high energy plasma interaction with different materials of interest in fusion devices (e.g., experimental simulation of plasma-wall interaction in ITER) $[3,4]$. In this connection, the main goals of the plasma surface interaction are experimental simulation of the expected ELMs (edge localized modes) and disruption loads in ITER and other fusion devices [5]. Intense thermal loads in fusion devices that occur during ELMs plasma disruptions and VDEs (vertical displacement events), will result in macroscopic erosion associated with the formation of cracks, melting, droplets, evaporation or sublimation. 
Surface interaction of pulsed high-power sources such as laser $[6,7]$, ion $[8,9]$, and electron $[10,11]$ beams, low pressure arc discharges and plasma flows [12-14] has been intensively studied up to now. The ion or plasma pulses can transport some material species to the target that may play an important role in the modification of a given target material. This depends both on the processed material and on the type, dose, and energy of the particle species. A pulsed plasma source can be customized to become the most suitable device for goal-oriented surface modification. An effective surface modification will be accessible if power parameters of plasma flows ensured both the rapid heating of the treated surface and maintaining of necessary temperature levels for a sufficient time until completion of physicochemical transformations without warming the underlying bulk and disturbing its structure and properties. The CPF can be used as a surface alloying tool capable of processing a coating/substrate system (e.g., a 1-5 $\mu \mathrm{m}$ thick film deposited on a substrate). In this process, a deep alloying of the substrate $(\sim 10-25 \mu \mathrm{m})$ by elements of the coating can be achieved, with solid solutions and chemical compounds being made between elements of the substrate and the coating [15-18]. The resulting surface properties are unlikely to be reproduced by available techniques.

Among the broad range of research areas related to the use of CPF, particular interest is being shown in the creation of new materials based on silicon, namely, metal silicides $[16,17,19]$. Silicides are widely used in micro and nano and optoelectronics and are applied as catalysts in the formation of nanotubes. Formation of transition metal silicides is of a high interest because of their stability, high melting points, excellent oxidation and corrosion resistances, and good mechanical strength at elevated temperatures. One of the methods for obtaining metal silicides is to dope a silicon surface layer with a metal via concentrated energy flux effect on the "coating-substrate" system. Thermal, mechanical, and radiation effects of CPF pulses provide nonequilibrium conditions for structural and phase transformations and the formation of novel low-dimensional structures in the surface layers of solids. CPF treatment of a thin metal layer (e.g., Fe, Ti, Ni, Zr, Mo) on a silicon substrate successfully made it possible to form metal silicides in the near-surface layer [16, 19-21].

In our previous study, CPF interaction with $\mathrm{Ta} / \mathrm{Si}$ and $\mathrm{Ti} / \mathrm{Si}$ systems were individually reported [17,22]. In CPF treatment of $\mathrm{Ti} / \mathrm{Si}$ [17], $\mathrm{Ti}_{5} \mathrm{Si}_{3}$ was formed after $\mathrm{CPF}$ action. This silicide was present overall range of used energy density. Among various metal silicides, the Mo-Si and Ti-Si compounds have been extensively studied. Other silicides, such as those related to the transition metals (V, $\mathrm{Nb}$, and $\mathrm{Ta}$ ) in the $\mathrm{Vb}$ group, have received relatively little attention. The melting point of Ta $(3293 \mathrm{~K})$ is high and comparable with the boiling temperature of silicon (3538 $\mathrm{K})$. In this case, equilibrium phase diagrams of the Ta-Si system show full intersolubility of components in the liquid phase and negligible solubility in the solid state, which makes mixing difficult. Taking into account a broad spectrum of compounds and phases produced in the Ta-Si system and extremely non-equilibrium conditions of phase formation by the CPF treatment, analysis of $\mathrm{Ta}$ film/ $\mathrm{Si}$ presents a complicated problem. Thus, CPF treatment of the "tantalum layer-silicon substrate" system was also carried out [22]. This recent work performed in a nitrogen atmosphere at the pressure of $400 \mathrm{~Pa}$, and successfully resulted in the formation of hexagonal crystalline tantalum-rich silicides in the near-surface layer.

The purpose of this work is to study the possibility of multicomponent alloying of a silicon substrate with the both metal coatings (i.e. Ta and Ti) with nitrogen a plasma forming substance by variations in CPF parameters. Although, numerous studies of silicide formation were carried out but, most of them are related to one metal in contact with $\mathrm{Si}$ while here we report the CPF treatment of the systems containing two metals (Ta and $\mathrm{Ti}$ ) and $\mathrm{Si}$.

\section{Methods and Experiments}

\subsection{Magneto Plasma Compressor (MPC) Setup and Discharge Mechanism}

Figure 1 (a) shows the electrode system of the MPC which consists of a conically shaped copper central electrode (cathode) with a divertor on the top, and a cylindrical outer electrode (anode) made of eight copper rods symmetrically positioned along a circle.

The discharge development of MPC can be divided into four phases: (i) discharge breakdown and plasma acceleration along the cathode conical part; (ii) radial plasma compression and relaxation of the accompanied plasma flow oscillations; (iii) quasi-stationary state of the CPF; (iv) decay of the plasma flow followed by afterglow effects. The CPFs became sustainable 10-20 $\mu$ s after the beginning of the discharge. As schematically demonstrated in fig. 1 (b) plasma flow is compressed due to the interaction between the longitudinal component of current $I_{z}$ swept away from the discharge device, and the intrinsic azimuthal magnetic field $B_{\varphi z}$, as well as due to the dynamic pressure of the plasma flow converging to the system axis (the inertial compression).

The stability of the CPF is achieved by a cylindrical discharge symmetry and homogeneous discharge current distribution through the surface of the electrodes. The discharge symmetry is achieved by a special sectional formation of the condenser bank energy supply and appropriate connection design. The discharge device of the MPC is situated in a vacuum chamber. A mechanical vacuum pump is used to evacuate the vacuum chamber below $1 \mathrm{~Pa}$; and then the chamber is filled with a working gas at given pressures (e.g., 10 to $10000 \mathrm{~Pa}$ ) and the MPC works at the residual gas regime.

Energy from a capacitor bank is transferred to the plasma through the magnetic field. The plasma is accelerated and, therefore, its kinetic energy is increased. Due to plasma compression its enthalpy is enhanced. After the plasma 
leaves the compressed zone, its total energy is again transferred into the plasma kinetic energy. During this second phase, an ionization zone is established in the region of the acceleration channel having a minimum cross-section. A sufficient number of ions produced by the swept-away current in the external region behind the electrode system are introduced into the acceleration channel sustaining the ion current transfer.

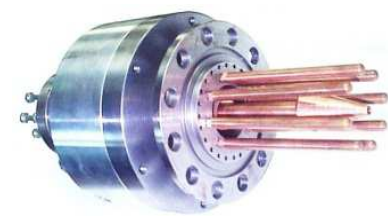

(a)

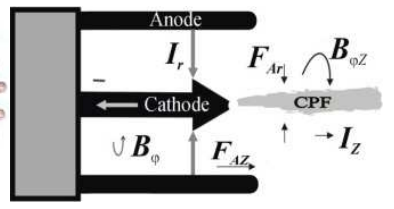

(b)

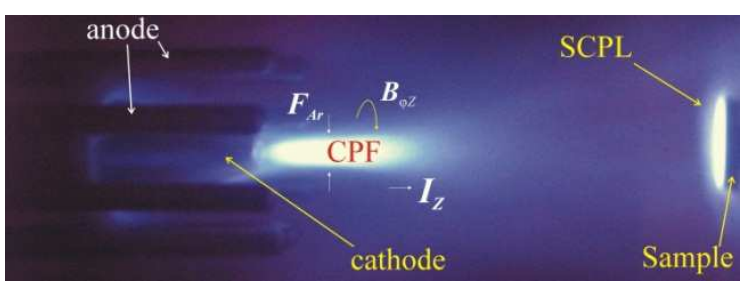

(c)
Figure 1. (a) MPC device and its electrods (anode as 8 rods and centeral conical cathod), (b) schematical demonstration of generated currents and magnetic fields, (c)action of a CPF on a target accompanied with development of a shock-compressed plasma layer (SCPL).

Figure 2 shows the electrical and energy parameters of discharge for the MPC operating in $\mathrm{N}_{2}$ gas and $\mathrm{U}_{0}=3 \mathrm{kV}$. One can see that the energy transfer from the capacitor bank to the discharge is terminated at the end of the first current half-period $(\sim 70 \mu \mathrm{s})$.

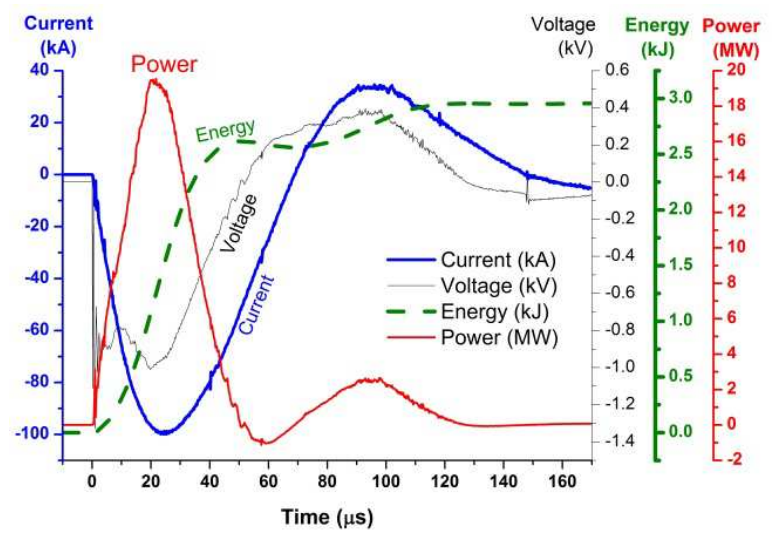

Figure 2. Discharge current, voltage, energy and power characteristics versus time for $U_{0}=3 \mathrm{kV}$ at the pressure of $400 \mathrm{~Pa}$ and by using the nitrogen as a working gas.

There are three main direction and application in surface modification of material by CPFs which can be marked out as following: (i) Direct treatment of materials [23-26], (ii) Mixing of a "coating-substrate" system [19,27-30], (iii) Thin film deposition and surface layer alloying by an additional component (e.g., powder) injected into the plasma flow [31-33].Plasma beams impinging on solid targets transfer their kinetic energy into both electronic and lattice excitations. Beam energy is converted quickly into atomic motion. Heat evolution in the target depends on beam parameters such as energy density, pulse duration, ion mass and energy, as well as on thermal properties of the irradiated material. The impact of compression plasma flows with the material surface can be accompanied by the following processes [30] ablation, melting of the surface layer, liquid phase mixing under temperature and pressure gradients (in case of non-uniform element composition along the depth); rapid cooling and crystallization of a modified layer.

As seen in fig.1 (c) and shown in our previous spectroscopic and shadowgraph studies, two interrelated plasma areas of intense radiation are observed during the discharge $[34,35]$. One of them corresponds to the CPF whose composition is primarily determined by the used working gas. The second one is a developed shock-compressed plasma layer (SCPL). The SCPL composition is defined by both the working gas and the target material, whose contributions depend on the exposure conditions and thermophysical characteristics of the material.

Radiation of the SCPL features intensive continuum caused by recombination and bremsstrahlung. Thus, the interaction process between the $\mathrm{CPF}$ and the target is governed in a self-consistent manner by dynamic pressure of the incident flow and gas-kinetic pressure of plasma spreading in the shock-compressed surface layer being formed. This layer shields the target from direct action of the CPF. Due to thermalization of kinetic energy of the compressed flow upon its slowdown, the SCPL heats up (convective heating), which, along with radiation of shock-compressed plasma (radiative heating), causes rapid heating of the target surface layer elements and initiates their diffusion of into substrate.

\subsection{Experiments on $\mathrm{Ta} / \mathrm{Ti} / \mathrm{Si}$ system}

As the substrate, a single crystal silicon wafer with the (100) orientation was used. A thin film of tantalum and titanium (thickness $\sim 1 \mu \mathrm{m}$ ) was respectively deposited by using ion beam sputtering technique (for Ta) and a vacuum arc facility (for Ti). The coating-substrate system was exposed to CPF pulses. Table 1, shows the treatment regimes.

Table 1. Parameters of CPF treatment of Ta/Ti film on Si samples.

\begin{tabular}{cccc}
\hline $\begin{array}{c}\text { Sample( } \\
\#)\end{array}$ & $\begin{array}{c}\text { Number of } \\
\text { CPF pulses }\end{array}$ & $\begin{array}{c}\text { Deposited energy } \\
\text { density }\left(\mathbf{J} / \mathbf{c m}^{2}\right)\end{array}$ & $\begin{array}{c}\text { Initial voltage on } \\
\text { capacitor bank } \\
(\mathbf{k V})\end{array}$ \\
\hline 1 & untreated & - & - \\
2 & $\mathrm{n}=1$ & $\mathrm{E} 1=3$ & 2.5 \\
3 & $\mathrm{n}=3$ & $\mathrm{E} 1=3$ & 2.5 \\
4 & $\mathrm{n}=1$ & $\mathrm{E} 2=9$ & 3.5 \\
5 & $\mathrm{n}=1$ & $\mathrm{E} 3=13$ & 4.0 \\
\hline
\end{tabular}

The MPC operated in a "residual gas" mode: the pre-evacuated compressor chamber was filled with a plasma-forming gas (nitrogen) up to $400 \mathrm{~Pa}$ pressure. The 
samples were fixed at a distance of $12 \mathrm{~cm}$ from the cathode tip and exposed to a single CPF pulse as described in table 1 . The plasma flow parameters were as follows: pulse duration $t \sim 100 \mu \mathrm{s}$, electron concentration $(4-7) \times 10^{17} \mathrm{~cm}^{-3}$, plasma pressure and temperature $1.5 \mathrm{MPa}$ and $2-3 \mathrm{eV}$, respectively. The velocity of the plasma spreading throughout the surface, according to measurements by high-speed photographic methods, was $(5-6) \times 106 \mathrm{~cm} / \mathrm{s}$. Energy density absorbed by the target was measured by calorimetric methods and varied in the range between $3-13 \mathrm{~J} / \mathrm{cm}^{2}$ by choosing respective initial voltage $\left(U_{0}\right)$ on capacitor banks $(\mathrm{C}=1200 \mu \mathrm{F})$.

The surface morphology and cross-sectional structure of samples were studied via scanning electron microscopy (SEM) with use of an LEO1455VP microscope equipped with an energy-dispersive X-ray analyzer (EDX). Observations were performed in the compositional contrast mode. The phase compositions of the untreated and CPF treated samples were investigated by means of X-ray diffraction (XRD) analysis using a DRON 4-13 diffractometer with a Bragg-Brentano focusing geometry and $\mathrm{Cu} \mathrm{K} \mathrm{K}_{\alpha}$ emission.

\section{Results and Discussion}

\subsection{Simulation of Temperature Distribution}

The temperature profile in the near-surface layer plays an important role in the structural phase changes of CPF-treated samples. In order to estimate the temperature filed across the depth of the samples, a numerical solution of the heat conduction equation Eq. (1) for the $\mathrm{Ta} / \mathrm{Ti} / \mathrm{Si}$ system was carried out.

$$
\frac{\partial}{\partial x}\left(k(x, t) \frac{\partial T}{\partial x}\right)-\rho(x, T) C_{p e}(x, T) \frac{\partial T}{\partial t}=0
$$

Where $k$ is the thermal conductivity coefficient, $\rho$ is the density, and $C_{p e}$ is the equivalent heat capacity at constant pressure. We used $C_{p e}$ to consider the phase transition. In the equation, these quantities depend on the temperature of tantalum, titanium and silicon. The equivalent heat capacity is defined by Eq. (2).

$$
C_{p e}(x, T)=C_{p}(x, T)+L(x) \delta\left(T-T_{m}\right)
$$

where $\mathrm{L}$ is the latent heat of fusion of these three elements (i.e., Ta, Ti, and $\mathrm{Si}$ ). The singular Dirac-delta function, $\delta\left(T-T_{m}\right)$, is replaced by Gaussian-pulse function defined as Eq.(3).

$$
F(T)=\frac{1}{\sqrt{\pi \Delta T}} \exp \left[-\frac{\left(T-T_{m}\right)^{2}}{\Delta T^{2}}\right]
$$

In this equation, $\Delta \mathrm{T}$ is chosen to be $1.0 \mathrm{~K}$. The coordinate origin is assumed to be placed on the free surface of a metallic layer. The initial and boundary conditions are written as

$$
\left.T\right|_{t=0}=T_{0}
$$

$$
\begin{aligned}
& \left.\frac{\partial T}{\partial x}\right|_{t=0}=\left\{\begin{array}{l}
\frac{W}{k} \text { fort } \leq \tau, \\
0 \text { fort }>\tau,
\end{array}\right. \\
& \left.k_{1} \frac{\partial T_{1}}{\partial x}\right|_{x=d_{0}}=\left.k_{2} \frac{\partial T_{2}}{\partial x}\right|_{x=d_{0}}
\end{aligned}
$$

Here, $W$ is the power density absorbed in the sample, $\tau$ is the time of exposure to CPFs $(100 \mu \mathrm{s}), T_{0}$ is the initial temperature of a sample $(293 \mathrm{~K})$, and $d_{0}$ is the initial thickness of tantalum and titanium coating (each of them $\sim 1 \mu \mathrm{m}$ thick). Conditions (4)-(6) describe, respectively, the initial state of the coating-substrate system, the quasi-stationary effect of CPFs, and the heat flux continuity at the coating-substrate interface. In calculations, the power densities based on the data of calorimetric measurements were used. Hence, heat losses caused by radiation and convective exchange with an external medium were automatically taken into account.

The results of this calculation are demonstrated in fig. 3 (a) and (b). The melting point of the elements is shown as horizontally dotted lines. As seen in fig. 3 (b), even at highest energy density (i.e. $E_{3}=13 \mathrm{~J} / \mathrm{cm}^{2}$ ), the temperature across the surface layer exceeds the melting point of silicon and titanium, but does not reach the melting point of tantalum $(3293 \mathrm{~K})$. In addition, a high cooling rate $\left(\sim 10^{7} \mathrm{~K} / \mathrm{s}\right)$ and a maximum temperature gradient $\left(\sim 10^{7} \mathrm{~K} / \mathrm{m}\right)$ were estimated.

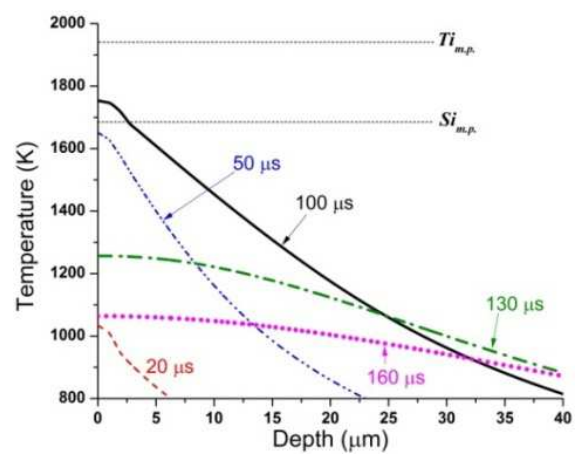

(a)

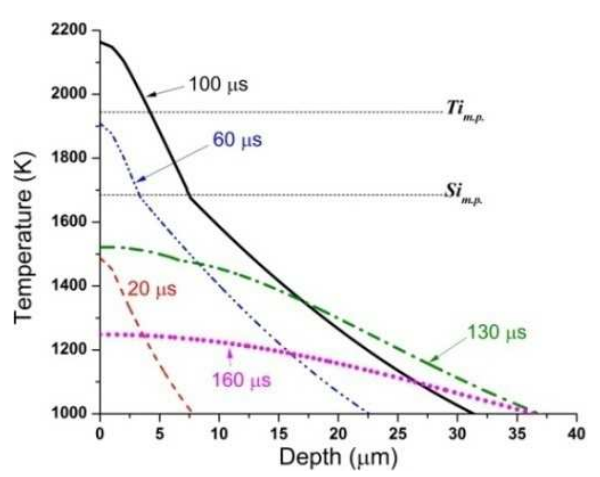

(b)

Figure 3. Temperature distributions across the near-surface layer of the $\mathrm{Ta} / \mathrm{Ti} / \mathrm{Si}$ system for (a) $9 \mathrm{~J} / \mathrm{cm}^{2}$, (b) $E_{3}=13 \mathrm{~J} / \mathrm{cm}^{2}$. The melting point of Si and Ti is indicated as horizontal dotted line.

However, an investigation on Ti-Si system under CPF treatment [20], confirmed that, under the impact of 
anuniform heat flux (without convection), the melting process starts at the threshold energy density $12 \mathrm{~J} / \mathrm{cm}^{2}$. It also showed that by doubling the energy density, the thickness of the molten alloy layer becomes 15 times thicker. It should be mentioned that the calorimetric experiment gives the average value of the energy density, and because of the inhomogeneity of the heat flux, the density of the plasma energy in local areas may be much greater than calculated values. On the other hand, according to the binary phase diagram of Ti-Si [36] and $\mathrm{Ta}-\mathrm{Si}$ [37], there are some eutectic compositions that provide the possibility of the formation of silicide phases at lower temperature than melting point. In other word, it is possible that a eutectic mixture and silicon can reach their melting temperatures at the coating-substrate interface before the free surface of a coating begins to melt. For instance, in the phase diagram of the Ta-Si system [37], when Ta concentration is 83 at.\% $(\mathrm{T}=2533 \mathrm{~K})$, the first eutectic $\left(\mathrm{Ta}_{3} \mathrm{Si}+\mathrm{Ta}\right)$ crystallizes, and when the Ta content is 38 at.\% $(\mathrm{T}=2233 \mathrm{~K})$, another eutectic $\left(\mathrm{TaSi}_{2}+\alpha \mathrm{Ta}_{5} \mathrm{Si}_{3}\right)$ crystallizes. This numerical calculation and upcoming EDX data confirm that the possibility of the formation of tantalum silicide is very weak. In contrast to this, titanium silicide can be produced at lower temperatures [36]. According to the phase diagram of Ti-Si system, an eutectic reaction of $(\mathrm{Ti}-\mathrm{Si})_{\mathrm{L}} \rightarrow \mathrm{Ti}+\mathrm{Ti}_{5} \mathrm{Si}_{3}$ occurs at a temperature of $1603 \mathrm{~K}$ and 8.5 wt.\% Si.

\subsection{SEM and EDX Analysis}

Figure 4 shows the SEM image of untreated $\mathrm{Ta} / \mathrm{Ti} / \mathrm{Si}$ sample where the polygonal grains can be seen. The EDX analysis of this sample (i.e., \#1), revealed the average concentration of tantalum and titanium to be 64.4 at.\%, 32.6 at.\%, respectively. Figures 5 and 6 show the SEM images (taken in the compositional contrast mode) for the CPF treated samples. To the right of each image, there is an EDX elemental profile along the assigned $\mathrm{AB}$ line that shows the distribution of the corresponding element.

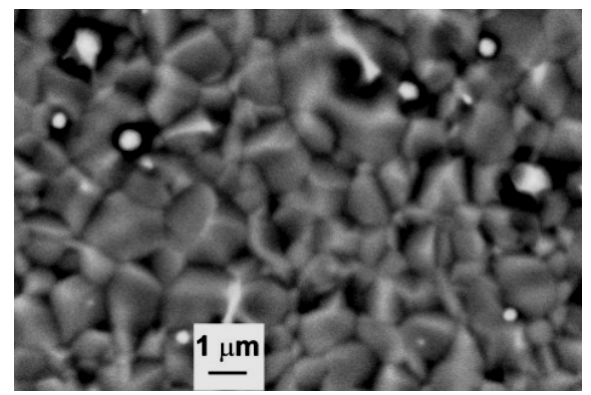

Figure 4. SEM image of untreated Ta/Ti/Si sample.

As seen in fig.5, surface morphology of treated sample even at lowest energy density has been dramatically affected by CPF action. The formation of this structure is caused by thermal effect of the CPF that leads to heating of the surface layer and initiates solid-state diffusion of metal into silicon. This is because the process of metal diffusion is faster and needs less energy than inverse silicon diffusion. Study of the surface morphology shows that CPF treatment has produced some cavities on the surface of the sample. The sizes of these cavities are $2-13 \mu \mathrm{m}$ (Fig. 5(a)). The cavities are formed due to the appearance of hydrodynamic instabilities and discharges between the shock-compressed plasma layer and the target surface due to the inhomogeneity of the heat flux transmitted from the plasma toward the target.

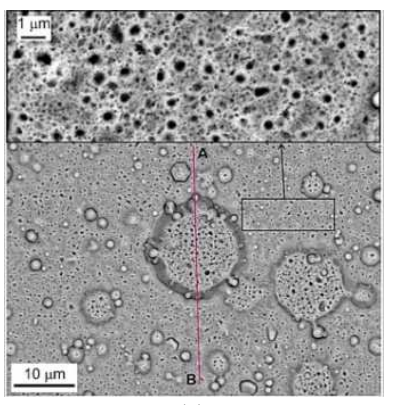

(a)

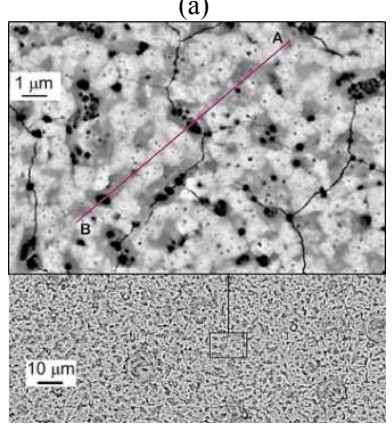

(c)

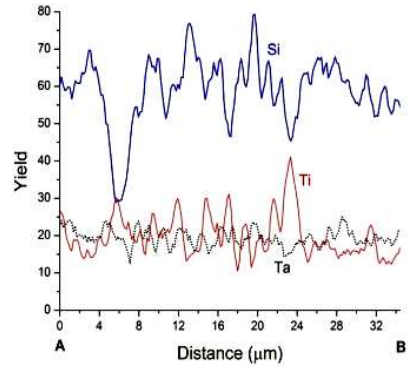

(b)

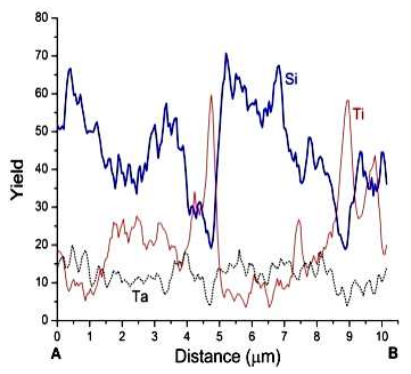

(d)
Figure 5. SEM images and corresponding EDX element profiles measured along the $A B$ line of samples: $(a, b) \# 2,(c, d) \# 3$.

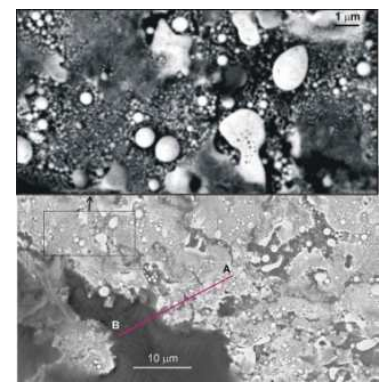

(a)

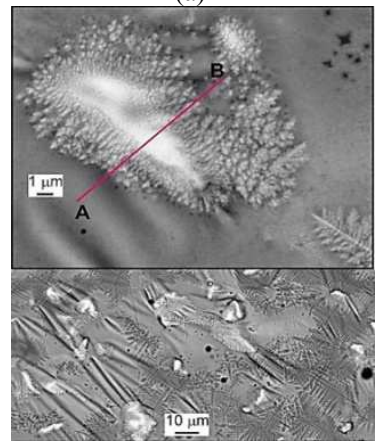

(c)

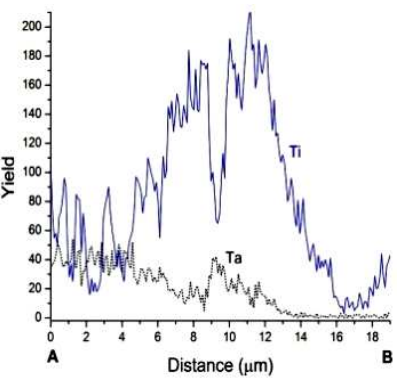

(b)

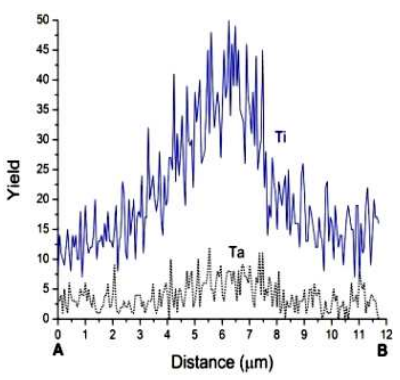

(d)
Figure 6. SEM images and corresponding EDX element profiles measured along the AB line of samples: $(a, b) \# 4,(c, d) \# 5$.

It seems that by increasing the number of plasma pulses the degree of structural uniformity on the surface is 
enhanced (Fig. 5(c)). Table 2 shows the EDX elemental concentration data from the surfaces of untreated and some of the treated samples. Either with an increase in the number of CPF pulses or absorbed energy density, the tantalum concentration reduces. There is not any visual evidence to confirm that tantalum has been melted for samples \#2 and \#3. This was numerically estimated. Therefore, the reduction of tantalum concentration in samples \#2 and \#3, can be related to the enhancement in the amount of the ablated products with each pulse.

Table 2. Mean element concentrations (in at.\%)obtained by EDX.

\begin{tabular}{llllll}
\hline \multirow{2}{*}{ Element } & Untreated & $\begin{array}{l}\mathbf{E}_{\mathbf{1}}=\mathbf{3} \\
\mathbf{J} / \mathbf{c m}^{2}, \\
\mathbf{n = 1}\end{array}$ & $\begin{array}{l}\mathbf{E}_{\mathbf{1}}=\mathbf{3} \\
\mathbf{J} / \mathbf{c m}^{\mathbf{2}}, \\
\mathbf{n = 3}\end{array}$ & $\begin{array}{l}\mathbf{E}_{\mathbf{2}}=\mathbf{9} \\
\mathbf{J} / \mathbf{c m}^{2}, \\
\mathbf{n = 1}\end{array}$ & $\begin{array}{l}\mathbf{E}_{\mathbf{3}}=\mathbf{1 3} \\
\mathbf{J} / \mathbf{c m}^{\mathbf{2}}, \mathbf{n}=\mathbf{1}\end{array}$ \\
\hline $\mathrm{Ta}$ & 64.4 & 63.9 & 56.6 & 18.9 & 3.3 \\
$\mathrm{Ti}$ & 32.6 & 33.6 & 43.4 & 67.6 & 17.0 \\
\hline
\end{tabular}

It is possible that the decrease in Ta concentration at elevated energy density (samples \#4 and \#5), is the ablation process. In contrast to Ta, titanium concentration is increased in samples \#2-\#4. One can be concluded that Ti atoms that had located under tantalum film have migrated toward the free surface as a result of melting and convection. At the highest energy density $\left(E_{3}\right)$, titanium concentration is reduced. This later reduction can be connected to both an increase in the ablated titanium and tantalum atoms together, and more homogeneous Ti distribution with depth. This claim has been previously confirmed that an increase in energy density leads to thickening of molten layer depth [17]. Increase in energy density to $E_{2}$ results in the formation of nanosized spherical particles (Fig. 6(a)). According to EDX analysis, the concentration of titanium in significantly higher that tantalum one (see Fig. 6(b) and Table 2). This regime of energy density seems to be the threshold of initiation of the melting process that starts from Ti-Si interface. Molten titanium and silicon atoms migrate to the surface through the cavities. Due to the plasma pressure and dynamic head of the compressed plasma flow spherical structures during fast solidification are formed. When the energy density is increased to $13 \mathrm{~J} / \mathrm{cm}^{2}$ (i.e. sample \#5), the formation of dendritic structure is observed (see Fig. 6(c)).

The SEM-studies in elemental contrast mode showed that dendrites consist of silicon while titanium and tantalum are located in interdendritic space (Fig. 6(d)). The formation of this structure is concerned with constitutional overcooling by rapid cooling of the intermixed liquid as previously estimated. Since the solubility of $\mathrm{Ti}$ and $\mathrm{Ta}$ in silicon is negligible, crystallization of silicon is accompanied by metal edging to liquid. According to the phase diagrams [36,37], solidification temperature of metal-rich liquid region is less than silicon solidification point. In other words, there is an overcooling phenomenon. Constitutional overcooling promotes stabilization of asperities on solidification front and their further development leading to the formation of dendrites. According to the concentration obtained by EDX analysis (Table 2), formation of stoichiometric titanium rich silicide $\left(\mathrm{Ti}_{5} \mathrm{Si}_{3}\right)$ for sample \#4 is possible.

\section{Phase Composition}

The results of the phase composition analysis are presented in Fig. 7. The diffraction lines of titanium and silicon are well seen on the diffraction pattern before treatment. The tantalum did not form a crystalline structure after its deposition on titanium. It probably exists as amorphous phase or as tantalum oxides that the corresponding peaks locate at lower angle than $2 \theta=20^{\circ}$. The reason may be connected with the method of Ta deposition that was different from titanium one. Titanium coating performed by vacuum arc coating, but tantalum deposited by ion beam sputtering technique from a powder target.

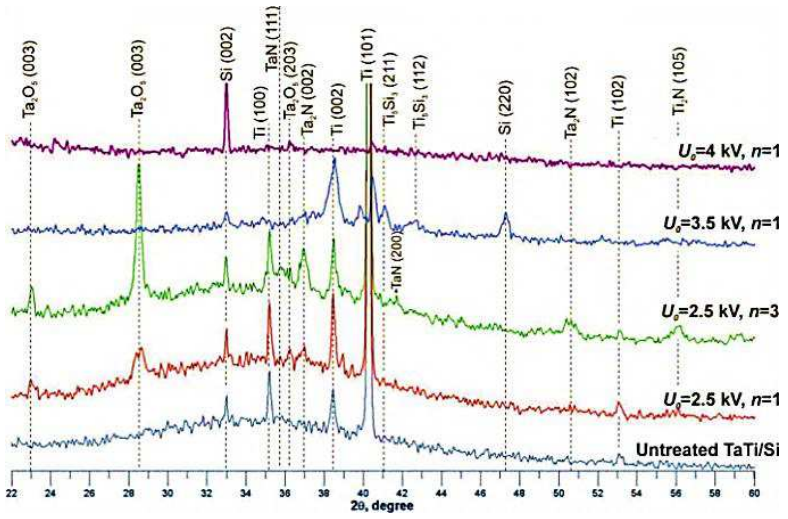

Figure 7. X-ray patterns of untreated and CPF treated Ta/Ti/Si samples at various regimes..

By single pulse CPF treatment at lowest energy density, one can see the formation of hexagonal crystalline phase of tantalum nitride $\left(\mathrm{Ta}_{2} \mathrm{~N}\right)$ and tantalum oxide $\left(\mathrm{Ta}_{2} \mathrm{O}_{5}\right)$. Formation of nitride and oxide phases after mixed layer crystallization is expected to proceed through diffusion of nitrogen and oxygen from the vacuum chamber at residual pressure. Increase in the number of CPF pulses, leads to an intensity rising of oxide and $\mathrm{Ta}_{2} \mathrm{~N}$ at $2 \theta=37^{\circ}$ as well as appearance of new nitride peaks (i.e., $\mathrm{TaN}, \mathrm{Ti}_{2} \mathrm{~N}$, and $\mathrm{Ta}_{2} \mathrm{~N}$ at $2 \theta=50.6^{\circ}$ ). This is because that enhancement of the number of pulses results in the growth of the maximum concentration of incorporated nitrogen and oxygen.

As seen in XRD pattern of sample \#2 and \#3, silicides were not detected. This was previously predicted as a result of numerical simulation and according to phase diagrams of Ta-Si and Ti-Si. By increasing the energy density to $\mathrm{E}_{2}=9$ $\mathrm{J} / \mathrm{cm}^{2}$ (sample \#4), formation of titanium rich silicide $\left(\mathrm{Ti}_{5} \mathrm{Si}_{3}\right.$ ) is observed. However, there is no evidence for the formation of tantalum silicide. This also was previously predicted that tantalum cannot reach the eutectic temperature to form tantalum silicide. Formation of titanium silicide is in consistence with the EDX data where the concentration of titanium was confirmed to be enough to form $\mathrm{Ti}_{5} \mathrm{Si}_{3}$.

A growth in the energy density (sample \#5) leads to diminish the previous peaks. It may intensify the ablation process and decreases the nitrogen and oxygen concentration in the SCPL, which reduces the amount of nitrogen capable of diffusing to the surface layer. In addition, the peak of titanium 
silicide dramatically decreased too. This later result can be connected with an increase in penetration depth and distribution of $\mathrm{Ti}$ in the bulk of the substrate. It seems that this later regime of treatment is not good for practical application.

It is known that, the most probable reaction corresponds to that characterized by the most negative difference in the enthalpy of formation (heat of formation; $\Delta \mathrm{H}_{\mathrm{f}}$ ) or Gibbs' free energy of the system. In comparison between $\mathrm{Ti}-\mathrm{Si}$ and Ta-Si compounds the formation of titanium-rich silicide (i.e. $\left.\mathrm{Ti}_{5} \mathrm{Si}_{3}\right)$ is the most probable one $\left(-\Delta \mathrm{H}_{298}=579.8 \mathrm{~kJ}\right)$ [38].This is also true for the formation of $\mathrm{Ta}_{2} \mathrm{~N}\left(-\Delta \mathrm{H}_{298}=\right.$ $270.9 \mathrm{~kJ})$ compared to $\mathrm{TaN}\left(-\Delta \mathrm{H}_{298}=252.4 \mathrm{~kJ}\right)[38]$.

\section{Conclusion}

The effect of compressed plasma flow on the two layers of tantalum and titanium $(\sim 1 \mu \mathrm{m}$ each $)$ on a silicon substrate was investigated under different treatment regimes. The main results include the following:

- $\quad$ Activation of solid-phase diffusion of metal (i.e., Ti) into silicon, coating-substrate interface melting (at energy density more than $9 \mathrm{~J} / \mathrm{cm}^{2}$ ), and liquid-phase mixing between titanium and silicon during a high temperature gradient, and fast solidification under CPF pressure.

- Formation of $\mathrm{Ta}_{2} \mathrm{~N}$ and $\mathrm{Ta}_{2} \mathrm{O}_{5}$ using single $\mathrm{CPF}$ pulse and $3 \mathrm{~J} / \mathrm{cm}^{2}$, as a result of working at nitrogen residual pressure.

- Promotion of $\mathrm{Ta}_{2} \mathrm{~N}$ and $\mathrm{Ta}_{2} \mathrm{O}_{5}$ and appearance of new nitride phases $\left(\mathrm{TaN}, \mathrm{Ti}_{2} \mathrm{~N}\right)$ as consequence of the enhancement of pulse numbers at the same energy density $\left(3 \mathrm{~J} / \mathrm{cm}^{2}\right)$.

- Creation of hexagonal crystalline titanium-rich silicide in the modified surface layer using single CPF pulse and energy of $9 \mathrm{~J} / \mathrm{cm}^{2}$.

- Formation of a dendritic structure as a result of concentration overcooling at the energy of $13 \mathrm{~J} / \mathrm{cm}^{2}$.

- The CPF thermal and mechanical action and consequently the fast heating (above the melting point of the substrate) and partial ablation of the near-surface layer in the SCPL, high cooling speed, re-crystallization play the main roles in explaining the results. These results demonstrate the potential for using CPF treatment as a low cost technique to form new silicon based material (e.g., tantalum nitride on $\mathrm{Ti} / \mathrm{Si}$ substrate, and titanium rich silicide) in one step by selecting a proper regime of treatment.

\section{References}

[1] V.M. Astashinskii, A.A. Mankovskii, L.Y. Minko, A.I Morozov, "Physical processes responsible for the different operating regimes of quasistationary high-current plasma accelerators "Sov. J. Plasma Phys. (Engl. transl.), vol. 18, pp. 47-51, 1992.

[2] V.M. Astashinskii, G.I. Bakanovich, E.A. Kostyukevich, A.M. Kuz'mitskii, A.A. Man'kovskii, L.Y. Min'ko, "Effects on compression-flux parameters from discharge characteristics in a compact magnetoplasma compressor," J. Appl. Spectrosc.,vol. 50, pp. 549-552, 1989.

[3] I.P. Dojčinović, "Plasma flow interaction with ITER divertor related surfaces," Journal of Physics: Conference Series,vol. 257, pp. 012033, 2010.

[4] I.P. Dojčinović, M.M. Kuraica, J. Purić, "Material surface damage by quasistationary compression plasma flow action," Vacuum, vol. 85, pp. 596-600, 2010.

[5] G. Federici, P. Andrew, P. Barabaschi, J. Brooks, R. Doerner, A. Geier, A. Herrmann, G. Janeschitz, K. Krieger, A. Kukushkin, A. Loarte, R. Neu, G. Saibene, M. Shimada, G. Strohmayer, M. Sugihara, "Key ITER plasma edge and plasma-material interaction issues," J. Nucl. Mater.,vol. 313-316, pp. 11-22, 2003.

[6] M. Jelani, S. Bashir, M.K.-u. Rehman, R. Ahamad, H. Faizanul, D. Yousaf, M. Akram, N. Afzal, M.U. Chaudhry, K. Mahmood, A. Hayat, S. Ahmad, "Effect of laser fluence on surface, structural and mechanical properties of $\mathrm{Zr}$ after irradiation in the ambient environment of oxygen," Eur. Phys. J. D,vol. 67, pp. 159, 2013.

[7] W. Pacquentin, N. Caron, R. Oltra, "Nanosecond laser surface modification of AISI 304L stainless steel: Influence the beam overlap on pitting corrosion resistance," Appl. Surf. Sci.,vol. 288, pp. 34-39, 2014.

[8] H. Akamatsu, T. Ikeda, K. Azuma, E. Fujiwara, M. Yatsuzuka, "Surface treatment of steel by short pulsed injection of high-power ion beam," Surf. Coat. Technol.,vol. 136, pp. 269-272, 2001.

[9] A.I. Pushkarev, Y.I. Isakova, "A gigawatt power pulsed ion beam generator for industrial applications," Surf. Coat. Technol.,vol. 228, Supplement 1, pp. S382-S384, 2013.

[10] S. Hao, B. Gao, A. Wu, J. Zou, Y. Qin, C. Dong, J. An, Q. Guan, "Surface modification of steels and magnesium alloy by high current pulsed electron beam," Nucl. Instrum. Methods Phys. Res., Sect. B,vol. 240, pp. 646-652, 2005.

[11] Y.-k. Gao, "Influence of pulsed electron beam treatment on microstructure and properties of TA15 titanium alloy," Appl. Surf. Sci.,vol. 264, pp. 633-635, 2013.

[12] I.M. Goncharenko, S.V. Grigoriev, I.V. Lopatin, N.N. Koval, P.M. Schanin, A.A. Tukhfatullin, Y.F. Ivanov, N.V. Strumilova, "Surface modification of steels by complex diffusion saturation in low pressure arc discharge," Surf. Coat. Technol.,vol. 169-170, pp. 419-423, 2003.

[13] J. Langner, J. Piekoszewski, Z. Werner, V.I. Tereshin, V.V. Chebotarev, I. Garkusha, L. Waliś, B. Sartowska, W. Starosta, W. Szymczyk, M. Kopcewicz, A. Grabias, "Surface modification of constructional steels by irradiation with high intensity pulsed nitrogen plasma beams," Surf. Coat. Technol.,vol. 128-129, pp. 105-111, 2000.

[14] B. Sartowska, J. Piekoszewski, L. Waliś, J. Senatorski, M. Barlak, W. Starosta, C. Pochrybniak, I. Pokorska, "Improvement of tribological properties of stainless steel by alloying its surface layer with rare earth elements using high intensity pulsed plasma beams," Surf. Coat. Technol.,vol. 205, Supplement 2, pp. S124-S127, 2011.

[15] V.V. Uglov, N.N. Cherenda, V.M. Anishchik, A.K. Stalmashonak, A.G. Kononov, Y.A. Petuhov, V.M. Astashinski, A.M. Kuzmitski, "Surface alloying of metals 
using a quasi-stationary plasma accelerator," High Temp. Mater. Processes (New York),vol. 11, pp. 383-391, 2007.

[16] V.V. Uglov, V.M. Anishchik, N.T. Kvasov, Y.A. Petukhou, V.M. Astashynski, A.M. Kuzmitski, "Structural and phase changes in iron-on-silicon treated by compression plasma flows," Vacuum, vol. 83, pp. 1152-1154, 2009.

[17] V.V. Uglov, N.T. Kvasov, R.S. Kudaktsin, Y.A. Petukhou, K.F. Ermalitskaya, V.M. Astashynski, A.M. Kuzmitski, "Compression plasma flows modification of surface layers in the system "Ti-Si": Phase composition, structure and element redistribution," Surf. Coat. Technol.,vol. 235, pp. 685-690, 2013.

[18] V.V. Uglov, V.I. Shymanski, N.N. Cherenda, V.A. Lyushkevich, V.M. Astashinskii, M.V. Astashinskaya, O.V. Reva, "Formation of titanium nickelide surface alloy under impact of compressive plasma flows on the nickel-titanium system," Inorganic Materials: Applied Research,vol. 4, pp. 475-480, 2013.

[19] V.V. Uglov, R.S. Kudaktsin, Y.A. Petukhou, N.T. Kvasov, A.V. Punko, V.M. Astashynski, A.M. Kuzmitski, "Mass transfer in "metal layer-silicon substrate" systems under the action of compression plasma flows," Appl. Surf. Sci.,vol. 258, pp. 7377-7383, 2012.

[20] V.V. Uglov, N.T. Kvasov, Y.A. Petukhov, R.S. Kudaktin, N.N. Koval', Y.F. Ivanov, A.D. Teresov, V.M. Astashinskii, A.M. Kuz'mitskii, "Structural phase changes in a titanium-silicon system modified by high-current electron beams and compression plasma flows," J. Surf. Invest.,vol. 6, pp. 296-302, 2012

[21] V.V. Uglov, N.T. Kvasov, Y.A. Petukhov, N.N. Koval', Y.F. Ivanov, A.D. Teresov, "Structure and phase composition of a chromium-silicon system modified by high-current electron beams," J. Surf. Invest.,vol. 6, pp. 67-72, 2012.

[22] A.H. Sari, V.M. Astashynski, A.M. Kuzmitski, Y.A. Petukhov, V.V. Uglov, "Phase transformations in Ta-Si system induced by compression plasma flow," The European Physical Journal - Applied Physics,vol. 65, pp. 10801, 2014.

[23] Z. Ac'imovic'-Pavlovic', K. Raic', I. Belic', "Modification of piston surfaces by compressed plasma flow," Protection of Metals and Physical Chemistry of Surfaces,vol. 47, pp. 797-802, 2011.

[24] V.M. Astashynski, S.I. Ananin, A.S. Emelyanenko, E.A. Kostyukevich, A.M. Kuzmitzky, S.P. Zhvavy, V.V. Uglov, "Bulk periodic structures formation on monocrystalline silicon surface under the action of compression plasma flows," Appl. Surf. Sci.,vol. 253, pp. 1866-1872, 2006.

[25] N.N. Cherenda, V.V. Uglov, V.M. Anishchik, A.K. Stalmashonak, V.M. Astashinski, A.M. Kuzmickii, A.V. Punko, G. Thorwath, B. Stritzker, "Modification of high-speed steels by nitrogen compression plasma flow: Structure, element composition, tribological properties," Surf. Coat. Technol.,vol. 200, pp. 5334-5342, 2006.

[26] V.V. Uglov, G.E. Remnev, A.K. Kuleshov, V.M. Astashinski, M.S. Saltymakov, "Formation of hardened layer in WC-TiC-Co alloy by treatment of high intensity pulse ion beam and compression plasma flows," Surf. Coat.
Technol.,vol. 204, pp. 1952-1956, 2010.

[27] N.N. Cherenda, V.I. Shymanski, V.V. Uglov, V.M. Astashinskii, A.M. Kuz'mitskii, N.N. Koval', Y.F. Ivanov, A.D. Teresov, "Formation of zirconium-titanium solid solutions under the action of compression plasma flows and high-current electron beams," Inorganic Materials: Applied Research,vol. 3, pp. 365-370, 2012.

[28] N.N. Cherenda, V.V. Uglov, V.I. Shymanski, V.M. Astashynski, A.M. Kuzmitski, "Modification of chromium/titanium system phase composition and mechanical properties by compression plasma flows," J. Optoelectron. Adv. M.,vol. 12, pp. 749-753, 2010.

[29] N.S. Tarasyuk, V.V. Uglov, N.N. Cherenda, V.A. Ukhov, "Alloying of structural steel with molybdenum and titanium under the action of compression plasma," Inorganic Materials: Applied Research,vol. 2, pp. 540-544, 2011.

[30] V.V. Uglov, V.M. Anishchik, N.N. Cherenda, A.K. Stalmashonak, V.M. Astashinski, A.M. Kuzmickii, E.A. Kostyukevich, A.V. Kovyazo, "Mixing of chromium/carbon steel by compressive plasma flows," Vacuum,vol. 78, pp. 489-493, 2005.

[31] V.M. Astashynski, S.I. Ananin, V.V. Askerko, E.A. Kostyukevich, A.M. Kuzmitski, V.V. Uglov, N.N. Cherenda, V.M. Anishchik, Y.V. Sveshnikov, V.V. Astashynski, N.T. Kvasov, A.L. Danilyuk, A.V. Punko, Y. Pauleau, "Deposition of nanostructured metal coatings on the modified silicon surfaces in the magnetoplasma compressor," Vacuum,vol. 78, pp. 157-160, 2005.

[32] V.V. Uglov, V.M. Anishchik, N.N. Cherenda, Y.V. Sveshnikov, V.M. Astashynski, E.A. Kostyukevich, A.M. Kuzmitski, V.V. Askerko, "The formation of a tungsten containing surface layer in a carbon steel by compression plasma flow," Surf. Coat. Technol.,vol. 202, pp. 2439-2442, 2008.

[33] V.V. Uglov, V.M. Anishchik, N.N. Cherenda, Y.V. Sveshnikov, V.M. Astashynski, E.A. Kostyukevich, A.M. Kuzmitski, V.V. Askerko, G. Thorwath, B. Stritzker, N.T. Kvasov, L.A. Danilyuk, "The formation of low-dimensional structures by compressive plasma flows," Surf. Coat. Technol.,vol. 200, pp. 297-300, 2005.

[34] V.M. Astashinskii, G.I. Bakanovich, L.Y. Min'ko, "Visible and near-infrared emissivity of a compressed plasma flow," J. Appl. Spectrosc.,vol. 40, pp. 372-375, 1984.

[35] V.M. Astashynskii, M.M. Kuraica, J. Puric, "Plasma dynamic processes accompanying high energy compression flows interaction with surfaces", 21 st SPIG The Physics of Ionized Gases. Vinca Institute of Nuclear Sciences, Belgrade, Serbia and Montenegro, 2003, pp. 263-276.

[36] D. Bandyopadhyay, "The Ti-Si-C system (Titanium-Silicon-Carbon)," J PhsEqil and Diff,vol. 25, pp. 415-420, 2004.

[37] M.E. Schlesinger, "The Si-Ta (silicon-tantalum) system," Journal of Phase Equilibria,vol. 15, pp. 90-95, 1994.

[38] E.A. Brandes, G.B. Brook, C.J. Smithells, Smithells metals reference book, Butterworth-Heinemann, (1998). 